\title{
Evaluation Of Demographic And Clinicopathological Characteristics Of Panreatic Adenocarcinoma Patients
}

\section{Pankreas Adenokarsinomlu Hastaların Demografik Ve Klinikopatolojik Özelliklerinin Değerlendirmesi}

\author{
Kaan Helvacı ${ }^{1}$, Ümmügül Üyetürk ${ }^{2}$, Özlem Sönmez ${ }^{3}$, İbrahim Türker ${ }^{1}$, Ülkü Yalçıntaş Arslan ${ }^{1}$ \\ ${ }^{1}$ Ankara Onkoloji Eğitim Ve Araştırma Hastanesi, Medikal Onkoloji Bölümü \\ ${ }^{2}$ Abant İzzet Baysal Üniversitesi Tıp Fakültesi, Medikal Onkoloji Bölümü \\ ${ }^{3}$ Yeditepe Üniversitesi Tıp Fakültesi, Medikal Onkoloji Bölümü
}

\section{ÖZET}

AMAÇ: Pankreas kanserleri hastalarının tanı anında sadece \%15-20'si cerrahi olarak çıkarılabilir aşamada olup \%52'sinde yaygın hastalık \%26'sında bölgesel yayılım mevcuttur (1). Pankreas kanserinin bir yıllık genel sağ kalım oranı \%26, beș yıllık ise \% 6'dır (2). Bu çalışmanın amacı Türkiye'de merkezi bir bölgede bulunan ve referans merkez olarak kabul edilen Ankara Onkoloji Eğitim Araştırma Hastanesi’ne başvuran pankreas adenokanserli hastaların klinikopatolojik özelliklerinin incelenmesidir.

GEREÇ VE YÖNTEM: Çalı̧̧ma için Ankara Onkoloji Eğitim ve Araştırma Hastanesi'nde 2007-2011 tarihleri arasında izlenmiş 121 erkek ve 72 kadından oluşan toplam 193 pankreas adenokanseri hastası retrospektif olarak tarand1.

BULGULAR: Hastaların 26'sına (\%13,5) küratif rezeksiyon uygulanmışı, 54 hasta (\%28) lokal ileri çıkarılamaz, 113 hasta ise $(\% 58,5)$ metastatik evredeydi. Tüm grup için $(\mathrm{n}=193)$ ortanca sağ kalım süresi 6 ay olarak bulundu. Yaşın, ortanca yaş olan 61 den büyük olması, ECOG performans durumunun 3 ve üzerinde değer olması, başlangıçta kilo kaybı olması, başlangıçta karın ağrısı olması, tümör gradının yüksek olması, tümörün lokal ileri veya metastatik olması, başlangıç metastaz bölgesinin periton veya karaciğer dışı olması, başlangıçta çoklu metastaza sahip olunması sağ kalıma anlamlı olumsuz yönde etkilemekteydi. Küratif opere edilen hastalar dışlanarak çıkarılamaz ve metastatik hastalar için bakılan CA19-9 değerinin ortanca değer olan 616'nın üzerinde olması kötü sağ kalım ile ilişkili idi $(\mathrm{p}=0,021)$. Metastatik aşamada kemoterapi almış olmak en iyi destek tedavisine bariz olarak üstündü. Ortanca sağ kalım kemoterapi almayan kol için 1 ay $(0,2-1,7)$ iken almış olan kolda $7(4,7-9,3)$ ay idi $(\mathrm{p}<0,0001)$. Lokal ileri çıkarılamaz grupta ise bu fark gösterilemedi.

SONUÇ: Hastaların klinik ve demografik incelenmesi neticesinde daha önceden yapılmış çalışmalarla genellikle benzer sonuçlara ulaşılmıştır. Hastalardaki ortanca yaşın dünya ortancasına göre düşük olması, Türkiye'de sigaraya başlama yaşının daha erken olması ile ilişkili olabileceğini akla getirmektedir. Tedavi kararı verirken yaş durumundan çok performans durumuna ve evresine göre karar vermek akıllıca olacaktır.

ANAHTAR KELİMELER: Pankreas adenokarsinomu, gemsitabin, sisplatin

\section{ABSTRACT}

OBJECTIVE: In patients with pancreatic cancer twenty-six percent are locally advanced, $52 \%$ are metastatic and only 20 $15 \%$ are surgically removable at the time of diagnosis (1). One-year overall survival rate of pancreatic cancer is $26 \%$ while 5 year overall survival rate is only $6 \%$ (2) The aim of this study is to analyze the clinicopathological features of the pancreatic adenocarcinoma patients who admitted to the Ankara Oncology Training and Research hospital.

METHODS: Total 193 pancreatic adenocarcinoma patients, including 72 women and 121 men, who were followed in Ankara Oncology Training and Research Hospital between dates 2007-2011, were evaluated retrospectively.

RESULTS: Twenty-six of the patients $(13,5 \%)$ had undergone curative resection, 54 patients $(28 \%)$ with locally advanced disease were unresectable, while 113 patients $(58,5 \%)$ had metastatic disease. For the entire group (n=193), median survival time was 6 months. Older age (more than median "61"), low performance status (ECOG $\geq 3$ ), weight loss or abdominal pain on admission, high grade tumor, locally advanced or metastatic disease, metastasis other than peritonea or liver, multiple metastases at the time of diagnosis were the parameters which significantly affect survival negatively. After excluding the curatively operated patients, high levels of Ca 19-9 (higher than median value:616) were associated with poor survival in patients with locally advanced or metastatic disease $(\mathrm{p}=0,021)$. Chemotherapy was significantly superior to best supportive care in the metastatic disease. Median overall survival in patients treated with chemotherapy versus best supportive care was 7 months $(4,7$ to 9,3$)$ and 1 month $(0,2$ to 1,7$)$ respectively ( $p<0,0001)$. There was no significant difference in overall survival with chemotherapy versus best supportive care in locally advanced unresectable group.

CONCLUSION: As a result of demographic and clinical examination of patients, we generally reached similar conclusions with previous studies. Low median age of the disease may be associated with an earlier age of onset of smoking in Turkey. It would be wise to consider performance status and stage of the disease rather than the age of the patient while making treatment decisions.

KEY WORDS: pancreas adenocarcinoma, gemcitabine, cisplatin, 


\section{Giriş:}

Pankreas kaynaklı malignitelerin \%95'i ekzokrin pankreas kaynaklı olup \%85'i de adenokanserlerden oluşur (3). $\mathrm{Bu}$ sebeple pankreas kanseri denince akla öncelikle adenokanserler gelir. Pankreas adenokarsinomları erken evrelerden itibaren kötü prognozludur ve yoğun tedavilere rağmen sonuç genellikle küratif olmaz. Amerika Birleşik Devletleri (ABD)'nde insidans olarak 11. sırada olmasına karşın kansere bağlı ölümlerde pankreas kanseri erkeklerde sırasıyla akciğer, prostat, kolorektal kanserlerden sonra, kadınlarda ise akciğer, meme ve kolorektal kanserlerden sonra 4. sırada yer alır (2). Türkiye'de yıllık insidans (2013 verilerine göre, $100.000 \mathrm{de}$ ) erkeklerde 6,3 kadınlarda ise 3,6 olarak saptanmıştır (4).

Tanı anında hastaların \%52'sinde yaygın hastalık \%26'sında bölgesel yayılım mevcuttur ve hastaların ancak \%15-20'si cerrahi olarak çıkarılabilir aşamadadır (1). Pankreas kanserinin bir y1llık genel sağ kalım oranı $\% 26$, beş yıllık ise $\% 6$ 'dır (2). Yüzde 73 hasta 55-84 yaş arasındadır. Erkek / kadın oranı: $1,3 / 1$ civarında, siyah 1 rkta ise daha sik görülmektedir (5).

Hastalığın risk faktörleri ile ilgili bilinenler azdır. Sigara bırakıldığında pankreas kanseri gelişme riski \%25 azalmaktadır (6). İlişkisi bilinen ancak tam ispatlanamayan faktörler ise diyabet, kronik pankreatit ve yüksek vücut kitle indeksidir (7). Hastaların \%10'unda aile öyküsü mevcuttur (8). Ailesel pankreatitlerde (9), MEN-1 (10), ve VonHippel-Lindau sendromu olan kişilerde (11) pankreas kanseri riski artar. Tümör yerleşimi $(n=33,752) \% 56$ hastada pankreas başında, \%18 hastada gövde ve kuyruktadır, \%26's1 ise SEER verilerinde "bilinmeyen", "pankreatik kanal" gibi kodlanmıştır (12).

Karın ağrısı pankreas kanserli hastalarda en sık başvuru belirtisidir, ağrısız sarılıkla da gelebilirler. Laboratuvar bulguları özellik arz etmez. Pankreas kanseri hastalarının \%7585'inde CA19-9 seviyeleri yükselir. Safra yolu tıkanıklığı, intrensek karaciğer hastalığı veya iyi huylu pankretik hastalık olmadığı biliniyorsa $100 \mathrm{U} / \mathrm{mL}$ nin üzerindeki değerler özellikle pankreatik kanser açısından oldukça spesifiktir ve rezeke edilemez durum ile ilişkilidir (13,14). CA19-9 değerlerinin postoperatif düşüş hızıda nüks açısından bazal değerden daha anlamlıdır (14). CEA hastaların sadece \%40-45 kadarında yükselir.

Tanıda ERCP (özellikle sarılık durumunda, firçalama biopside yapılabildiğinden) veya EUS ile biopsi tercih edilir. Transkütanöz biopsiler peritoneal ekim riskinden dolay1 irrezektable durumda tarcih edilmelidir (15). Görüntülemede klavuzlar trifazik multidedektör BT ile ince kesitli görüntüleme yapılmasını önermektedir (16). TNM evrelemesi prognostik olsa da tedavi kararı rezektabiliteye göre verilmektedir.

Pankreas kanserinde primer tedavi yöntemi cerrahidir. Baş kısmındakilerde pankreatikoduodenektomi, kuyruk kısmındakilerde distal pankreatektomi uygulanabilirken gövde k1smindakiler genellikle çıkarılamaz olarak kabul edilir. Günümüzde superior mezenterik veya portal venin invazyonu da rezeksiyon için mutlak bir kontrendikasyon olmaktan çıkmıştır (17). Laparoskopik periton y1kamas1/biyopsisi ile $\% 20$ aktif metastaz saptanabilmektedir (18).

Pankreas kanserinde henüz bir neoadjuvan tedavi yaklaşımı standart tedavi olarak kabul görmemiş olsa da NCCN tarafindan sınırda çıkarılabilir hastalarda kategori 2B olarak önerilmektedir (16). Lokal ileri hastalıta kemoradyoterapi ve kemoterapi ile ilgili pozitif çalışmalar bulunsa da kemoradyoterapi daha çok sistemik tedavi sonrasında halen çıkarılamaz durumda olan ve halen sistemik yayılım yapmamış hastalarda tercih edilmektedir (19). GITSG, ESPAC, CONKO çalışmaları da dahil olmak üzere bazı çalışmalarda, opere edilebilir hastalığın cerrahi rezeksiyonundan sonra kemoterapinin, tek başına veya radyoterapi ile birlikte, ortanca sağ kalımda anlamlı iyileşme sağlayabileceğini ileri sürülmüştür (20-25). Bu sebeple adjuvan tedavide kemoterapi ve kemoradyoterapinin her ikisi de öneriler arasındadır.

\section{Gereç ve yöntem:}

Çalışmaya Ankara Onkoloji Eğitim ve Araştırma Hastanesi'nde 2007-2011 tarihleri arasında izlenmiş 121 erkek ve 72 kadından oluşan toplam 193 pankreas adenokarsinom hastası alındı. Tüm hastaların yaş, cinsiyet, 
yaşadığ1 yer, sigara öyküsü, geçirilmiş operasyon, eşlik eden hastalık öyküsü gibi sosyo-demografik özellikleri ve pankreas karsinomu ile ilgili aldığ 1 tedavi özellikleri geriye dönük olarak incelendi. 6 ayda $\% 10$ 'dan fazla kilo kaybı olması kilo kayb1 var olarak kabul edildi. İstatiksel analizde değerlendirme için bilgisayar tabanlı bir istatistik programı kullanıldı. Sayısal değerler çoğunlukla ortanca olarak verildi. Sayısal değişkenlerin analizinde uygun olan yerlerde Cross Tabulation, Kruskal-Wallis ve Mann-Whitney $U$ testi kullanıldı. Oransal verilerin karşılaştırılmasında Pearson-Chi-Square testleri kullanıldı. Sağ kalım analizinde Kaplan-Meier testi kullanıldı. Sayısal değerler arasındaki ilişki incelenmesinde Pearson korelasyon analizi kullanıldı. P değerinin 0.05 altında olması anlamlı olarak kabul edildi.

\section{Bulgular:}

Genel özellikleri Tablo-01 de belirtilen toplam 193 pankreas adenokarsinomlu hastanın ortanca yaşı 61 (20-83) idi. Hastaların 72 si kadın, 121'i (\%63) erkekti. Hastalar en çok (\%69) İç Anadolu Bölgesi'nde yaşayan bireylerdi.

Başlangıçta kilo kaybı hastaların \%58,5'inde $(n=103)$,karın ağrısı \%85'inde $(n=149)$, kolestaz \%38'inde $(\mathrm{n}=73)$ mevcuttu ve cinsiyet açısından farklılık izlenmedi. Pankreas baş bölgesi yerleşimli tümörlerde kolestaz anlamlı derecede daha fazla görülmekteydi $(p<0,0001)$. Tanı anında \%79 hastanın performans durumu (PS) 0-2, \%21 hastanın ise PS 3-4 idi. Cinsiyet, yaş, CA19,9 düzeyleri ve primer tümör lokalizasyonu ile PS arasında ilişki gözlenmedi ( $\mathrm{p}=0,9, \mathrm{p}=0,48, \mathrm{p}=0,67$ ve $\mathrm{PS}=0,34$, s1ras1 ile). Tümör lokalizasyonlarına göre değerlendirildiğinde baş bölgesi tümörleri anlamlı miktarda daha fazlayd $1(\mathrm{p}=0,002)$.

Ortanca CA19-9 düzeyi 616 (min-mak:11,298,361) olarak bulundu. Cinsiyet, PS, Diyabetes Mellitus (DM), kolestaz, sigara, kilo kaybı, tümör lokalizasyonu ve grad ile CA19-9 düzeyi arasında anlamlı bir ilişki gösterilemedi. Hastaların 26'sına $(\% 13,5)$ küratif rezeksiyon uygulanmışt1, 54 hasta (\%28) lokal ileri çıkarılamaz, 113 hasta ise $(\% 58,5)$ metastatik evredeydi. Hastaların çoğunda tanı iğne biyopsisi ile elde edildiğinden gradı bilinen az sayıda hasta vardı $(n=33)$. Bu hastaların \%70'i iyi-orta \%30'u kötü gradlı adenokarsinom idi. Metastatik evrede tanı alan hastaların \%80'inde $(n=90)$ başlangıçta sadece karaciğer metastazı vardı. Geriye kalan metastatik hastaların periton metastazlılar $\% 7$, akciğer metastazlılar $\% 2$, lenf nodu metastazlilar \%1, çoklu metastazı olanlarda \%10'luk bir grubunu oluşturmaktaydı

\section{Uygulanan Tedavi Modaliteleri}

Yirmi altı hastaya küratif rezeksiyon yapılmıştı $(\% 13,5)$. Hastaların \%23'ünde cerrahi sinır (CS) pozitif iken \%57'sinde lenf nodu pozitifliği vardı. $\mathrm{Bu}$ hastaların 18 'i takip süresinde nüks etti. Nüks gözlenen hastalardan sadece 4'ü palyatif kemoterapi aldi.

Lokal ileri evre rezeke edilemeyen 54 (\%18) hastanın 13'ü hiç tedavi almamıştı.

Lokal ileri rezeke edilemeyen 20 hasta, tan anında metastatik 65 hasta ve küratif opere edilmiş ama nüks gözlenmiş 4 hasta 1 . basamak kemoterapi almıştı. Birinci basamak palyatif tedavi alan hastalarda ortanca kür say1s1 5 (1-9) idi.

Tablo-02'da hastalarda evrelere göre uygulanan tedaviler, tablo-03 de ise birinci basamakta sadece kemoterapi (KT) alan hastalarda uygulanan rejimler belirtilmiştir.

\section{Lokal ileri ve metastatik hastalık için} uygulanan tedavi ile elde edilen yanit oranlart Yanitlar lokal ileri ve metastatik grup birlikte ele alınarak incelendi (tablo-04). Birinci basamakta tek başına gemsitabin alan hastalarda k1smi yanıt oran1 $\% 3,4 \quad(n=3)$, gemsitabin-sisplatin kombinasyonu alan kolda ise \%25,8 $(\mathrm{n}=23)$ olmuştu. Sadece bir hasta kapesitabin-oksaliplatin (XELOX) kombinasyon kemoterapisi almıştı bu hastada kısmi yanıt sağlanmıştı. 
Tablo-01: Pankreas Adenokanserli Hastaların Klinik ve Tümör Karakteristikleri

\begin{tabular}{|c|c|c|c|c|c|}
\hline & $\begin{array}{l}\text { Rezektabl } \\
\text { Hastalar }\end{array}$ & $\begin{array}{ll}\text { Lokal } & \text { ileri } \\
\text { Hastalar } & \end{array}$ & $\begin{array}{l}\text { Metastatik } \\
\text { Hastalar }\end{array}$ & $\begin{array}{l}\text { Tüm } \\
\text { Hastalar }\end{array}$ & $\begin{array}{l}\text { p(tüm } \\
\text { hastalar } \\
\text { için) }\end{array}$ \\
\hline HastaSayısı (n) & $n=26$ & $\mathrm{n}=54$ & $\mathrm{n}=113$ & $\mathrm{n}=193$ & \\
\hline Ortanca Yaş & 56 & 64 & 60 & 61 & \\
\hline $\begin{array}{ll}\text { Cinsiyet } & \\
& \text { Kadın } \\
\text { Erkek }\end{array}$ & $\begin{array}{l}13(\% 50) \\
13(\% 50)\end{array}$ & $\begin{array}{l}22(\% 40) \\
32(\% 60)\end{array}$ & $\begin{array}{l}37(\% 33) \\
76(\% 67)\end{array}$ & $\begin{array}{l}72(\% 37) \\
121(\% 63)\end{array}$ & 0,221 \\
\hline $\begin{array}{r}\text { Tümör } \\
\text { Lokalizasyonu } \\
\text { Baş } \\
\text { Gövde } \\
\text { Kuyruk }\end{array}$ & $\begin{array}{l}21(\% 81) \\
4(\% 16) \\
1(\% 4)\end{array}$ & $\begin{array}{l}38(\% 70) \\
15(\% 28) \\
1(\% 2)\end{array}$ & $\begin{array}{l}56(\% 54) \\
24(24) \\
23(\% 22)\end{array}$ & $\begin{array}{l}115(\% 63) \\
43(\% 23) \\
25(\% 14)\end{array}$ & 0,002 \\
\hline Grade & $\begin{array}{l}2(\% 17) \\
9(\% 75) \\
1(\% 8)\end{array}$ & $\begin{array}{l}5(\% 56) \\
1(\% 11) \\
3(\% 33)\end{array}$ & $\begin{array}{l}4(\% 33) \\
2(\% 17) \\
6(\% 50)\end{array}$ & $\begin{array}{l}11(\% 33) \\
12(\% 36) \\
10(\% 31)\end{array}$ & $<0,0001$ \\
\hline $\begin{array}{rr}\text { Sigara } & \\
& \text { Var } \\
& \text { Bırakmış } \\
& \text { Yok }\end{array}$ & $\begin{array}{l}3(\% 50) \\
1(\% 17) \\
2(\% 33)\end{array}$ & $\begin{array}{l}9(\% 32) \\
6(\% 21) \\
13(\% 46)\end{array}$ & $\begin{array}{l}24(\% 43) \\
11(\% 20) \\
21(\% 37)\end{array}$ & $\begin{array}{l}36(\% 40) \\
18(\% 20) \\
36(\% 40)\end{array}$ & 0,891 \\
\hline $\begin{array}{l}\text { Performans } \\
\text { Durumu }\end{array}$ & $\begin{array}{l}25(\% 96) \\
1(\% 4)\end{array}$ & $\begin{array}{l}48(\% 89) \\
6(\% 11)\end{array}$ & $\begin{array}{l}79(\% 70) \\
34(\% 30)\end{array}$ & $\begin{array}{l}152(\% 79) \\
41(\% 21)\end{array}$ & 0,001 \\
\hline DM & $\begin{array}{l}12(\% 46) \\
14(\% 54) \\
\end{array}$ & $\begin{array}{l}33(\% 61) \\
21(\% 39) \\
\end{array}$ & $\begin{array}{l}49(\% 43) \\
64(\% 57) \\
\end{array}$ & $\begin{array}{l}94(\% 49) \\
99(\% 51) \\
\end{array}$ & 0,095 \\
\hline $\begin{array}{r}\text { Hipertansiyon } \\
\text { Var } \\
\text { Yok }\end{array}$ & $\begin{array}{l}1(\% 4) \\
25(\% 96)\end{array}$ & $\begin{array}{l}16(\% 30) \\
38(\% 70)\end{array}$ & $\begin{array}{l}26(\% 23) \\
87(\% 77)\end{array}$ & $\begin{array}{l}43(\% 22) \\
150(\% 78)\end{array}$ & 0,033 \\
\hline Kolestaz & $\begin{array}{l}11(\% 42) \\
15(\% 58)\end{array}$ & $\begin{array}{l}24(\% 44) \\
30(\% 56) \\
\end{array}$ & $\begin{array}{l}38(\% 34) \\
75(\% 66) \\
\end{array}$ & $\begin{array}{l}73(\% 38) \\
120(\% 62)\end{array}$ & 0,374 \\
\hline CA19-9 (Ortanca) & 38 & 886 & 700 & 616 & 0,056 \\
\hline
\end{tabular}

Tablo-02: Pankreas Adenokanserli Hastalarda Evrelere Göre Uygulanan Tedavi Modaliteleri

\begin{tabular}{|l|c|c|c|c|c|c|}
\hline & KRT & KT & KRT+KT & RT & RT+KT & Tedavi yok \\
\hline Adjuvan (n=26) & $8(\% 31)$ & $6(\% 23)$ & $6(\% 23)$ & $1(\% 4)$ & $2(\% 8)$ & $3(\% 11)$ \\
\hline $\begin{array}{l}\text { Çikarilamaz } \\
\text { (n=54) }\end{array}$ & $6(\% 11)$ & $20(\% 37)$ & $12(\% 22)$ & $3(\% 6)$ & & $13(\% 24)$ \\
\hline $\begin{array}{l}\text { Metastatik } \\
(\mathbf{n = 1 1 3})\end{array}$ & & $\begin{array}{c}65+4^{* *} \\
(\% 59)\end{array}$ & & $3(\% 2)^{*}$ & & $45(\% 39)$ \\
\hline
\end{tabular}

* Pankreatik bölgeye ağrı palyasyonu amaçlı uygulanmış. **Metastatik olarak nüks eden hastalar. KT: Kemoterapi, KRT: Kemoradyoterapi, RT: Radyoterapi 
Tablo-03: Birinci Basamakta Sadece Kemoterapi Alan Hastalarda Uygulanan Rejimler

\begin{tabular}{|c|c|c|c|}
\hline & Gemsitabin & $*$ G-P & Diğer KT \\
\hline $\begin{array}{c}\text { Adjuvan } \\
(\mathbf{n = 2 6})\end{array}$ & & $12(\% 86)$ & $2(\% 14)$ \\
\hline $\begin{array}{c}\text { Nükste } \\
(\mathbf{n}=18)\end{array}$ & & $3(\% 75)$ & $1(\% 25)$ \\
\hline $\begin{array}{c}\text { Çıarımamaz } \\
(\mathbf{n = 2 0})\end{array}$ & $6(\% 30)$ & $14(\% 70)$ & \\
\hline $\begin{array}{c}\text { Metastatik } \\
(\mathbf{n}=\mathbf{6 5})\end{array}$ & $12(\% 18,5)$ & $53(\% 81,5)$ & \\
\hline
\end{tabular}

*G-P: Gemsitabin + Sisplatin, (Nüks ve Adjuvanda burada gösterilmeyen kalan hastalar diğer tedavi modaliteleri ile tedavi edilmişlerdir o sebeple oranları burada verilmemiştir)

Tablo-04: Birinci Basamakta Sadece Kemoterapi Alan Hastalarda(lokal ileri ve metastatik hastalar) Radyolojik Yanit

\begin{tabular}{|l|c|c|c|c|}
\hline & Gemsitabin & $*$ G-P & **Xelox & Toplam \\
\hline Kismi Yanıt & $3(\% 3,4)$ & $23(\% 25,8)$ & $1(\% 1,1)$ & $27(\% 30,3)$ \\
\hline Stabil Yanıt & $7(\% 7,9)$ & $21(\% 23,6)$ & 0 & $28(\% 31,5)$ \\
\hline Progresyon & $8(\% 9)$ & $26(\% 29,2)$ & 0 & $34(\% 38,2)$ \\
\hline Toplam & $18(\% 20,2)$ & $70(\% 78,7)$ & $1(\% 1,1)$ & $89(\% 100)$ \\
\hline
\end{tabular}

*G-P: Gemsitabin + Sisplatin **Xelox: Kapesitabin + Oksaliplatin

\section{Să̆ kalım Sonuçları:}

\section{Hasta ve Tümör Karakteristikleri ile Să kalım İlişkisi}

Tanı esnasındaki ECOG performans durumu sağ kalımı güçlü bir şekilde etkiliyordu. Performans durumu 0-2 olan 152 hastanın $\% 21,1$ halen hayatta iken PS 3-4 ile başvuran hastaların neredeyse tamamı ölmüştü $(\mathrm{p}<0,0001)$. PS:0-2 olanlarda ortanca genel sa $\breve{g}$ kalım (oGSK) 9 ay, PS:3-4 olanlarda ise 2 ay olarak bulundu $(\mathrm{p}<0,0001) \quad$ (Şekil-1). Operasyon ile tümörün küratif amaçla çıkarıldığı hastalarda ortanca sağ kalım süresi rezeke edilemeyen lokal ileri hastalık ile başvuran hastalardan 2 kat, metastatik hastalık ile başvuran hastalardan ise 4,5 kat daha uzundu (ortanca 18 aya karşın 9 ve 4 ay, $\mathrm{p}<0,0001)$.

Kilo kaybı sorgulanmış olan hastaların 103'ünde kilo kayb1 vardı ve bu hastalar kilo kaybı olmayanlar ile kıyaslandığında anlamlı olarak daha kısa yaşam süresine sahipti (ortanca 4 aya karşın 9 ay, $\mathrm{p}<0,0001$ ) (şekil-2).
Benzer şekilde tanı anında karın ağrısı öyküsü bilinen 149 hastanın sağ kalım sonuçları semptomatik olmayan hastaya kıyasla anlamlı olarak kötü idi (ortanca 6 aya karşın 9 ay, $\mathrm{p}=0,019)$ (şekil-3).

DM, hipertansiyon varlığ 1 ve kolestatik sarılık ile başvurma sıklığı, primer tümör bölgesi ile sağ kalım arasında anlamlı ilişki gösterilemedi ( $\mathrm{p}=0,77, \mathrm{p}=0,31$ ve $\mathrm{p}=0,87,0.78$ siras1 ile). Tan1 esnasında lökositoz varlığının sağ kalımı kötü etkileme eğilimi olsa da ( $\mathrm{p}=0,26)$, anemi ve trombositoz varlığının genel sağ kalım üzerine bir etkisi saptanmad $(\mathrm{p}=0,88, \mathrm{p}=0,67)$.

CA19-9 değeri ortanca değer olan 616'nın üzerinde ve altında olan hastaların sağ kalım sonuçları değerlendirildiğinde lokal ileri rezeke edilemeyen ve metastatik hastalar $(n=167)$ için yüksek CA19-9 değeri kötü sağ kalım ile ilişkili idi (oGSK: 5 ay vs 8 ay), $(\mathrm{p}=0,021)$, şekil-4).

Sigara içme/içmeme durumu bilinen 90 hasta vardı ancak anlamlı sağkalım ilişkisi gösterilemedi. 


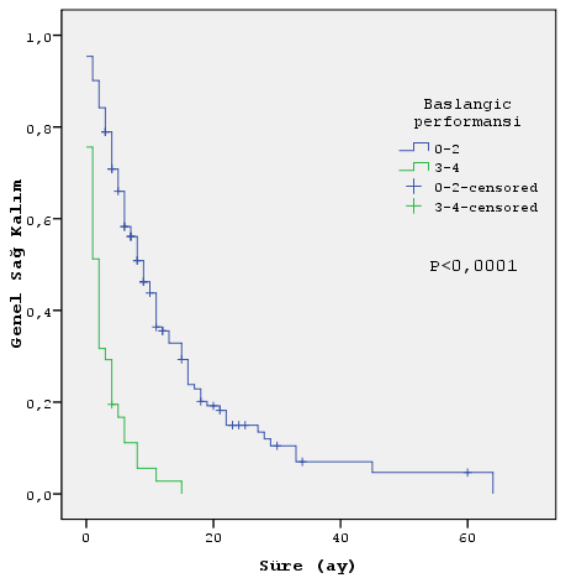

Şekil-1: Pankreas adenokanserli hastalarda başlangıç performans durumuna göre kaplan-meier sağ kalım eğrisi

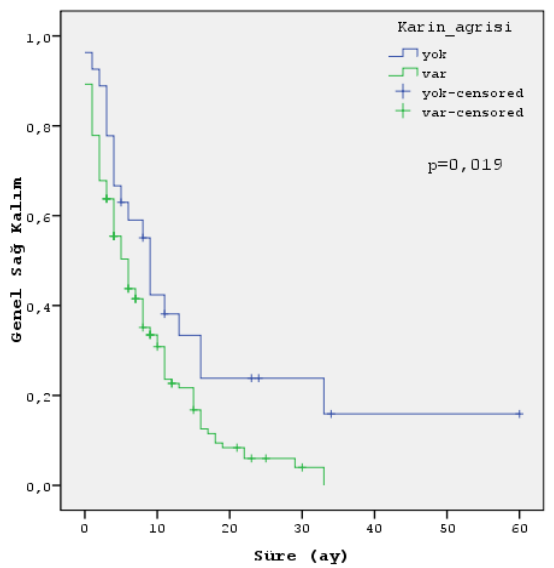

Şekil 3:Pankreas adenokanserli hastalarda tanı anında karın ağrısı durumuna göre kaplan-meier sağ kalım eğrisi

\section{Tedavi İle İlişkili Sağ kalım Sonuçları:}

\section{Opere edilmiş hastalar}

Küratif cerrahi yapılan 26 hasta için ortanca genel sağ kalım süresi 18 (minimum 11,5 maksimum 24,5) ay ve ortanca hastalıksız sağ kalım süresi 13 (minimum 10,3 -maksimum 15,6) ay olarak bulunu. Analiz yapıldığında küratif opere olmuş 26 hastanın sadece 10'u $(\% 38,5)$ hayattaydı. Operasyon sonrasi adjuvan kemoterapi verilmiş olan hastalarda ortanca sağ kalım 21(minimum 15,4-maksimum 26,6) ay idi. Adjuvan Kemoradyoterapi (KRT) alanlar ve almayanlar arasında sağ kalım açısından (15 ay vs 11 ay) anlamlı fark gösterilemedi $(p=0,67)$.Pozitif $\mathrm{CS}$ olan hastalarla olmayanlar arasinda anlamlı OS veya PFS fark1 gösterilemedi $(p=0,92)$. Lenf nodu pozitif olanlar negatif olanlara göre kötü

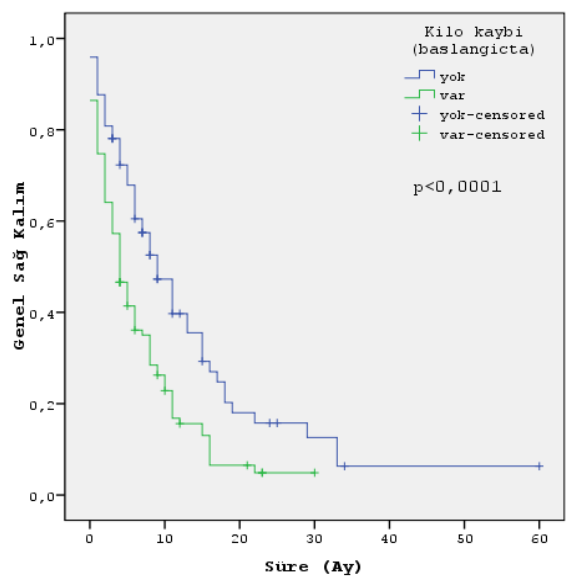

Şekil-2:Pankreas adenokanserli hastalarda tanı anında kilo kaybı durumuna göre kaplan-meier sağ kalım eğrisi

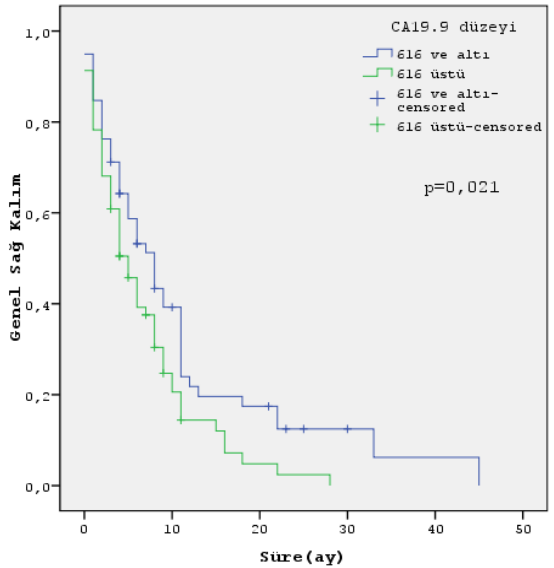

Şekil-4:Lokal ileri rezeke edilemeyen ve metastatik pankreas adenokanserli hastalarda tedavi öncesi ortanca serum ca19-9 düzeyine göre kaplan-meier sağ kalım eğrisi

sağ kalıma sahiptiler (o GSK: 16 ay vs 29 ay) ancak bu durum anlamlılığı ulaşmadı $(\mathrm{p}=0,28)$.

\section{Lokal ileri rezeke edilemeyen hastalar}

Lokal ileri rezeke edilemeyen 54 hastanın ortanca sağ kalımı 6 (minimum 0maksimum.19) ay olmuştu ve herhangi bir tedavi alanlar ile almayanlar arasında istatiksel anlaml fark yoktu $(\mathrm{p}=0,231)$ KRT ve KT'yi beraber alan 12 lokal ileri çıkarılamaz durumda olan hastanın \%50'den fazlasinın $(\mathrm{n}=7)$ önce KRT aldığı görüldü. Önce KT alanlarda ortanca GSK 15 ay iken önce KRT sonra KT alan kolda ortanca GSK 9 ay olarak bulunsa da olasılıkla hasta sayısının azlığına bağlı olarak aralarında anlamlı fark izlenmedi $(\mathrm{p}=0,5)$. 


\section{Metastatik hastalar}

Metastatik hastalık ile başvuran ve küratif opere olup sonra nüks eden toplam 131 hastanın 62'si destek tedavisi ile izlenmişti. Destek tedavi grubunun çoğunluğu analiz esnasında yaşamıyordu $(\% 91,1)$. Altmış dokuz hasta ise kemoterapi almıştı ve bu hastaların $\% 12,3$ 'ü hayatta idi. Altı aylık yaşam kemoterapi almayan kolda sadece \%0,9 iken alan koldaki hastaların yarısı hayatta idi. (şekil-5).

On sekiz hasta metastatik veya lokal ileri rezeke edilemeyen hastalık için 1. basamak gemsitabin, 70 hasta ise gemsitabin ve sisplatin tedavisi almıştı. Sadece bir hasta adjuvan gemsitabin aldığ 1 için metastatik 1. sıra oksaliplatin - kapesitabin almıştı, bu hasta kemoterapi gruplarını etkinlik karşılaştırmalarından dışlandı. Gemsitabin alanların halen 4 'ü $(\% 22,2)$ ve kombine tedavi alanların 11 'ü $(\% 15,7)$ hayatta idi. Her iki grup arasında ortanca sağ kalım süresi açısından sayısal bir farklılık var olsa da (5 aya karşın 8 ay) olasılıkla lokal ileri hastalık için yalnızca gemsitabin alan hasta sayısının sadece 6 olması nedeni ile optimal bir karşılaştırma yapılamadığg düşünüldü.(p=0,545).

Benzer şekilde, lokal ileri çıkarılamaz durumda ve metastatik olan gruplar ortak değerlendirildiğinde $(n=89)$ kemoterapi ile radyolojik kısmi yanıt veya stabil hastalık sağlanan hastaların sağ kalım sürelerinin birbirine yakın (ortanca 13'e (10,2-15,7) karşın $11(9,7-12,3)$ ay) ancak tedavi altında progresyon gelişen hastalarla karşılaştırıldığında (ortanca $4(3,1-4,8)$ ay) her ikisinin de belirgin şekilde uzun olduğu görüldü ( $<<0,0001)$ (Şekil-6)

Birinci basamakta verilen tüm tedaviler göz önüne alınarak klinik yanıtı değerlendirilmiş olan lokal ileri ve metastatik 113 hastanın 67'si $(\% 59,3)$ tedaviden klinik yarar sağlamıştı ve bu hastaların $18^{\prime} \mathrm{i}$ halen hayatta iken sağlanamamış olan hastaların sadece 2'si yaşıyordu $(\mathrm{p}<0,0001)$. (Şekil-7)
Metastatik hastalık nedeni ile kemoterapi almış hastalar (XELOX almış bir hasta dışarıda bırakılarak) analiz edildiğinde kemoterapi almış olmak en iyi destek tedavisine bariz olarak üstündü. Ortanca genel sağ kalım tedavi almayan kol için 1 ay $(0,2-1,7)$ iken almış olan kolda $7(4,7-9,3)$ ay idi $(\mathrm{p}<0,0001)$.

Metastatik hastalar için ortanca PFS 23 hafta (19-27) idi. Gemsitabin tek başına verildiğinde $(\mathrm{n}=12)$ ortanca PFS 9 hafta $(0,3$ 17,6) iken sisplatin tedaviye eklendiğinde( $(\mathrm{n}=56) \quad 25 \quad(18,0-31,9) \quad$ haftaya uzamıştı $(p=0,001)$. (Şekil-8) Tek başına gemsitabin almış hastalarda medyan genel sağ kalım 4 ay, sisplatin gemsitabin kolunda ise medyan 8 ay olarak bulundu $(\mathrm{p}=0,004)$ (Şekil9)

Progresif hastal1k esnasında halen PS 0-2 olan 24 hasta 2. sıra tedavi almıştı. İkinci basamak tedavi almış ve almamış hastalar arasında da sağ kalım açısından anlamlı bir fark vardı $(p=0,048)$. İkinci basamak tedavi alan hastalar oksaliplatin temelli olanlar(n=17) ve olmayanlar(n=7) olarak gruplandırıld 1 ancak iki grup arasında anlamlı bir fark bulunamadı $(\mathrm{p}=0,675)$

Metastatik pankreas adenokanserli hasta alt grubunda yapılan çoklu değişkenli analizde sadece evre, kilo kaybı, karın ağrisı ve başlangıç performans durumunun, başlangıç metastazının tekli veya çoklu olması, metastatik aşamada kemoterapi almak veya almamak ve ikinci sira kemoterapi alma durumunun sağ kalımla anlamlı ilişkisi devam etmekteydi. Kilo kaybı için p=0,008 (HR:0,62, \%95 CI: 0,43-0,88), karın ağrıs1 için $\mathrm{p}=0,046$ (HR:1,64, \%95 CI: 1,00-2,68), başlangıç PS için $p<0,001$ (HR:3,46, \%95 CI: 2,29-5,22), evre için $\mathrm{p}<0,001$ (HR:1,95, \%95 CI: 1,47$2,60)$, başlangıç metastazının tekli veya çoklu olmas1 için $\mathrm{p}<0,032$ (HR:5,11, \%95 CI: 1,1422,85), metastatik aşamada kemoterapi almak veya almama durumu için $\mathrm{p}<0,011$ (HR:0,35, \%95 CI: 0,16-0,78), ikinci sira kemoterapi alma durumu için p<0,014 (HR:0,41, \%95 CI: 0,20-0,83) olarak bulunmuştur. 


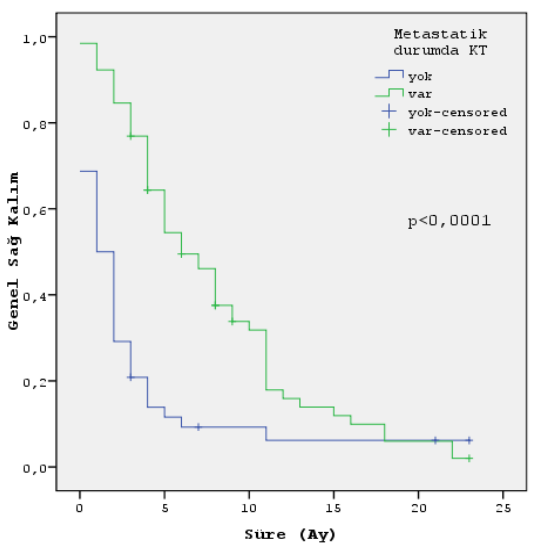

Şekil-5:Metastatik pankreas adenokanserli hastalarda kemoterapi alma durumuna göre kaplan-meier sağ kalım eğrisi

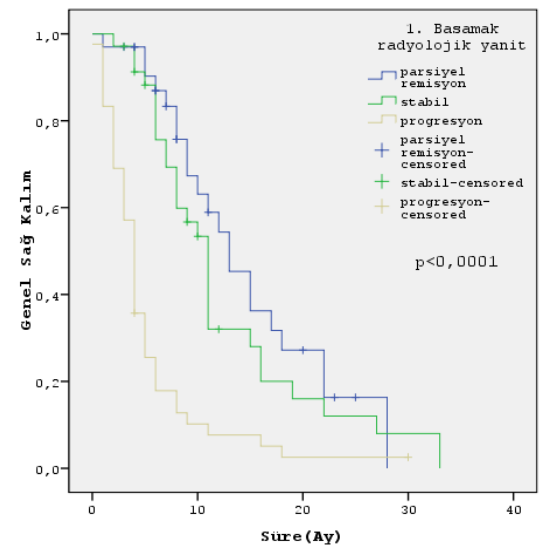

Şekil-6:Lokal ileri ve metastatik pankreas adenokanserli hastalarda 1.basamak kemoterapi ile sağlanan radyolojik yanıt durumuna göre kaplan-meier sağ kalım eğrisi

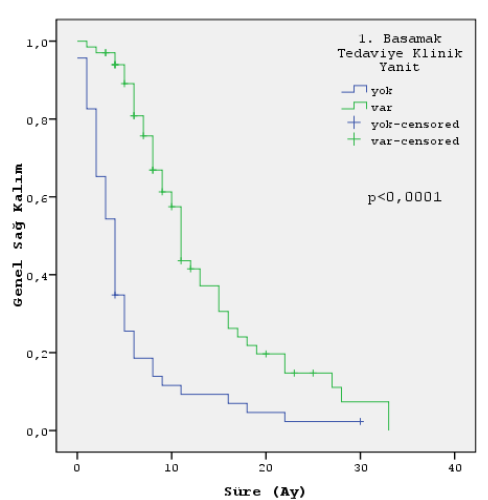

Şekil-7: Lokal ileri ve metastatik pankreas adenokanserli hastalarda 1.basamak tedavi ve klinik yanıt durumuna göre kaplan-meier sağ kalım eğrisi

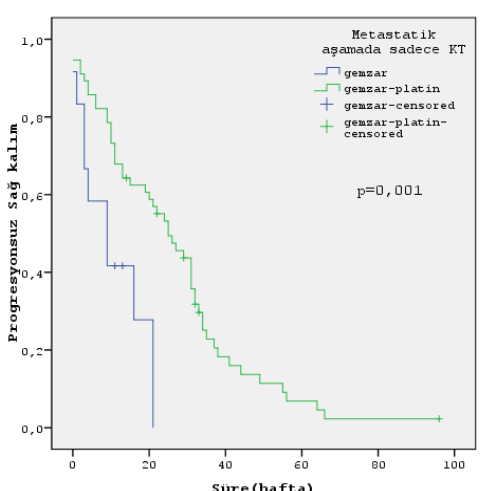

Şekil-8: Metastatik pankreas adenokanserli hastalarda verilen kemoterapi rejimine göre kaplanmeier progresyonsuz sağ kalım eğrisi

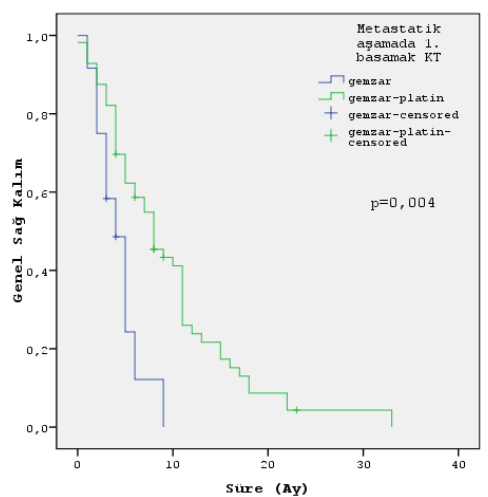

Şekil-9: Metastatik pankreas adenokanserli hastalarda uygulanan kemoterapi rejimine göre kaplan-meier genel sağ kalım eğrisi

\section{Tartışma:}

Bizim serimizde ortanca yaş Batı kaynaklarında bildirilen yaş ortalamasının yaklaşık bir dekat altındadır (26). Hasta grubumuzda kadınlarda 1 . basamak tedaviye erkeklere göre daha fazla kısmi yanıt ve stabil yanıt gösterdiklerini gördük (\%54 vs \%75). Bu durum belki genel olarak erkeklerde sigara içiminin daha fazla olması ile ilişkili olabilir. Xenograft fare modellerinde nikotin maruziyeti ile pankreas kanseri hücrelerinde gemsitabin direnci gelişebileceği gösterilmiştir ayrıca yine sigara ile ilişkisi bilinen mesane tümörü hücre serilerinde, yapılan bir çalışmada, sigara dumanının sisplatin direnci geliştirdiği gösterilmiştir $(27,28)$. Bizim çalışmamızda lokal ileri rezeke edilemeyen ve metastatik hastalıkla ilgili uygulanmış kemoterapilerin büyük bir çoğunluğunu sisplatin ile gemsitabin kombinasyonu oluşturuyordu.

Kilo kaybı, sarılık, ağrı, sigara kullanımına göre skorlama yapılan klinik bir çalışmada, yüksek klinik skora sahip olan hastalarda ortanca sağ kalım 6,3 ay iken düşük skorlu hastalarda 14,6 ay bulunmuştu (29). Çalışmamızda bu faktörlere ayrı ayrı bakıldığında başlangıçta kolestaz varlığı ve aktif sigara kullanımı açısından anlamlı bir sonuç elde edemedik ama kilo kaybı açısından bakıldığında ise kilo kaybı olan grupta sağ kalımın anlamlı derecede daha kısa olduğunu saptadık. Aynı şekilde karın ağrısı semptomu olanlarda sağ kalım, olmayanlardan anlamlı olarak daha kısaydı.

Serimizde sadece 26 hasta küratif rezeke edilebilmişti ve çalışmanın geriye dönük olmas1 nedeniyle homojen bir tedavi grubu oluşmamıştı, bu nedenle sadece cerrahi 
eksizyon yapılabilmiş hastalarda sağ kalım sonuçlarının lokal ileri ve metastatik hastalardan daha iyi olduğunu ortaya koymak dışında istatistiksel olarak anlamlı bir veri elde edemedik. Sadece 3 hasta herhangi bir adjuvan tedavi almamıştı ki bu durum gözlem kolu olarak hakkında karar vermek için de yeterli bir sayı değildi.

Adjuvan KRT sonrası KT almış olan grup ortanca 21 ay ile en uzun yaşayan hastaların olduğu gruptu ve literatürde elde edilen sağ kalım sonuçları ile uyumlu idi. KRT uygulamalarında çoğunlukla 5-FU tercih edilmişti. RT veriliş şekli ve dozu açısından modern uygulama teknikleri esas alınmıştı (BT ile planlama, konformal teknik, tek fazlı uygulama, ortanca 50,4 cGy). En fazla uygulanan adjuvan tedavi rejimi ise büyük faz 3 çalışmaların aksine tek ajan gemsitabin yerine gemsitabin sisplatindi(30). Hangi tedavi modalitesinin hangi hastalarda önce uygulanması gerektiği henüz yanıtlanmamış bir sorudur.

Destek tedavi ile KRT karşılaştırılan küçük bir Japon çalışmasında $(n=31)$ sağ kalımın KRT kolunda yaklaşık 2 kat yüksek olduğu (ortanca 13,2 karşın 6,4 ay, sırası ile), 1 yıllık sağ kalımin ise tedavi kolunda \%53 iken destek tedavi kolunda bir yıl yaşayan hasta olmadığ 1 bulundu (31). Bizim çalışmamızda lokal ileri çıkarılamaz olup herhangi bir tedavi uygulanan hastalar ile destek tedavi ile izlenenler arasında sağ kalım eğrileri izlendiğinde tedavi lehine bir görünüm var ise de olasilıkla hasta sayılarının azlığı ve tedavi modalitelerinin çeşitliliği nedeni ile istatistiksel fark yakalanamadi. Ayrica tedavi alan ve almayan gruptaki hastaların tümörlerinin grad, ilaç direnci gibi biyolojik özelliklerinin bilinmemesi nedeni ile de daha ileri yorum getiremiyoruz. Bu çalışmada lokal ileri rezeke edilemeyen hastalık hakkında açıklıkla söylenebilecek şey metastatik hastalara göre beklendiği üzere daha uzun süre yaşadıklarıdır.

Chauffert ve ark çalışmasında sisplatin ve 5FU ile eş zamanlı KRT sonrasında gemsitabin haftalık uygulaması ile sadece gemsitabin kolu karşılaştırılmıştı. Sadece kemoterapi kolunda ortanca GSK 13 ay ile KRT/KT koluna üstündü (ortanca 8,6 ay) (32). Bu sonuçlar KRT kolundakilerde tedavi daha toksik gitmesiyle erken araların verilmesiyle veya daha olasılıklı olarak yukarda belirtildiği üzere farklı tümör biyolojisine sahip hastaların aynı çalışma tedavisini almaları ile açıklanabilir. Bizim çalışmamızda lokal ileri rezeke edilemeyen hastalarda uygulandığı görülen KRT doz ve şeması bolus 5-FU ve konformal 50,4 cGy di. Hiç bir hastada gemsitabin radyo duyarlılaştırıcı olarak kullanılmamıștı, bu nedenle ne etkinlik ne de toksisitesi hakkında yorum yapamıoruz. Daha da önemlisi KRT alan hasta grubunun 6 gibi çok kısitlı bir örneklem sunuyor olması tek başına KRT'nin bizim populasyonumuzdaki etkinliği hakkında ileri bir yorum yapamamamızın en önemli nedenidir.

Tek ajan KT metastatik pankreas kanserinin standart yaklaşımıdır. Ancak aktif tek ajanların hiçbirisi ile elde edilen objektif cevap oranı \%10'nun üstünde değildir (33). En çok çalışılmış olan tek ajan ilaç 5-Fluorourasildir (FU). Gemsitabinin tek ajan kullanıldığ faz 2 çalışmasında $1000 \mathrm{mg} / \mathrm{m} 2$ haftada bir 7 hafta ilaç, bir hafta ara sonrasinda 1.8.15. günlerde ilaç, bir hafta ara verilerek kullanılmış, objektif cevap oranı \%11 olmasına karşın klinik fayda \%27 olarak bulunmuştu (ağrıda düzelme, PS stabil kalması ve kilo kaybının durması gibi). Sonraki çalı̧̧malarda, klinik fayda ve sağ kalım primer sonlanım noktasi olarak kullanıldı. Lokal ileri ve metastatik hastalıkta bu şema $5-\mathrm{FU} 600 \mathrm{mg} / \mathrm{m} 2$ haftalık uygulaması ile karşılaştırıldı her iki grupta da objektif yanıt olmasa da gemsitabin kolunda klinik fayda (\%24 vs \%5) ve 1 y1llik sağ kalım (\%18 vs \%2) daha fazlaydı (34).

Bizim çalışmamızda metastatik hastaların neredeyse yarısına KT verilememişti Tek başına gemsitabin ise sadece 12 metastatik hastaya verilmişti. Sonuçta KT almanın, ne almış olursa olsun, sağ kalımı anlamlı olarak etkilediğini gördük. Gemsitabin tek ajan ile karşılaştırıldığında kombine tedavi almış olmanın sağ kalım üzerine anlamlı bir katkısı vard1.

$\mathrm{Bu}$ sonuç kombinasyonun standart tek başına gemsitabin ile karşılaştırıldığında sağ kalım farkının gösterilemediği faz 3 çalışma verileri ile çelişmektedir, Heinemann ve arkadaşlarının çalışmasında 195 metastatik hasta gemsitabin ile gemsitabin-sisplatin olarak karşılaştırılmış her ne kadar gemsitabin-sisplatin ile progresyonsuz sağ kalım artmışsa da $(5,3$ ay vs $3,1$ ay $\mathrm{HR}=0,75 ; \quad \mathrm{P}=0,053)$ kombinasyon tedavisi kolunda sağ kalım farkı anlamlı değildi $(7,5$ ay vs 6 ay $\mathrm{P}=0,15)$. Yine de 
araştırıcılar 2 haftada bir uygulanan sisplatin ve gemsitabin tedavisinin etkin ve güvenli olduğunu öne sürmüşlerdi (35).

Colucci ve ark. çalışmasında lokal ileri ve metastatik 400 hastada gemsitabin ile gemsitabin ile kombine sisplatinin etkinliği karşılaştırıld1 (\%84'ü metastatik hasta). Ortanca sağ kalım 8,3 vs 7,2 ay idi (HR:1,10; \%95CI, 0,89-1,35; $\mathrm{P}=0,38$ ). Ortanca PSK her iki kol için de aynıydı. Klinik fayda açısından karşılaştırıldığında tek başına gemsitabin \%23 ile sisplatin + gemsitabin koluna $(\% 15,1)$ göre istatiksel olarak sinırda anlamlı bir fark gösteriyordu: Yazarların yorumlarına göre haftalık gemsitabine sisplatin eklemek prognoz açısından herhangi bir düzelme sağlamamıştı (36).

Tek ajan tedavi daha çok hastaların kötü performans1 göz önünde tutularak verilmişti. Performans durumu 0-2 olan hastalar genelde platin + gemsitabin beraber almıştı bu nedenle bu çalışmada metastatik hastalık için gemsitabin + platin tedavisinin gemsitabine karş1 gösterdiği sağ kalım üstünlüğünün yukarıda bahsedilen prospektif çalışmalarla çelişmesinin nedeni her iki kol arasında hasta sayısı ve PS açısından bir dengenin olmaması ile açıklanabilir. Ancak kliniğimizdeki gemsitabin/sisplatin uygulamas1 ve gemsitabin uygulamas1, gemsitabin için 1 . ve 8 . gün verilmek üzere $1000-1200 \mathrm{mg} / \mathrm{m} 2$ doz ile 21 günde bir, sisplatin $75 \mathrm{mg} / \mathrm{m} 21$. gün, 21 günde bir uygulama şeklindeydi. Literatürde bu şemanın pankreas kanserinde yapılmış diğer randomize çalışmalarla birebir karşılaştırmasına rastlayamadık. Bundan dolayı sağ kalım sonuçlarını diğer çalışmalardakine benzer oranlarda olmasına karşın her iki grup arasına oluşan sağ kalım farkına bir açılama getirmesi açısından dikkatle yaklaşmak gerektiğini düşünüyoruz. Ayrıca, bu çalışmada gemsitabin tek başına verilen hastalara göre gemsitabin kombinasyonu ile elde edilen hem klinik fayda hem radyolojik cevap oranları istatistiksel anlamlılığa ulaşamasa da sayısal olarak daha üstündü.

Gemsitabin ilk sıra tedavide kullanıldığında 2. sıra için bilinen bir standart tedavi seçeneği olmaması nedeni ile yayınlanmış çalışmalar 1şığında 2. sıra tedavide sıklıkla oksaliplatin içeren ve içermeyen floropirimidin kullanılmıştı. Bu çalışmaya alınan hastaların önemli bir kısmını oluşturan metastatik pankreas kanserinde hem 1 . hem de 2. sira sitotoksik tedavi destek tedavisine göre sağ kalım sonuçlarını iyileştirse de sonuçlar yüz güldürücü olmaktan uzaktır.

Çıkar Çatışması: Herhangi bir çıkar çatışması belirtilmedi.

\section{Referanslar:}

1. Jemal A, Siegel R, Ward E, Hao Y, Xu J, Thun MJ. Cancer statistics, 2009. CA Cancer J Clin. Jan;59(4):225-49

2. Jemal A, Siegel R, Xu J, Ward E. Cancer statistics, 2010. CA Cancer J Clin. Jan;60(5):277-300

3. Longo D, Fauci A, Kasper D, Hauser S, Jameson J, Loscalzo J. Harrison's Principles of Internal Medicine, 16th Edition. 2011. 537-539 p

4. Gultekin Murat, Boztas Guledal, Utku Simsek Ezgi ve ark. 2013 y1lı Türkiye Kanser İstatistikleri. Ankara; 2016

5. Howlader N, Noone AM, Krapcho M et al. Cancer Statistics Review, 1975-2012 - SEER Statistics. National Cancer Institute. Bethesda, MD

6. Fuchs CS, Colditz GA, Stampfer MJ, Giovannucci EL, Hunter DJ, Rimm EB, et al. A prospective study of cigarette smoking and the risk of pancreatic cancer. Arch Intern Med. 1996 Oct 28;156(19):225560

7. Maisonneuve P, Lowenfels AB. Risk factors for pancreatic cancer: a summary review of metaanalytical studies. Int J Epidemiol. 2015 Feb;44(1):186-98

8. Brune K, Abe T, Canto M, O'Malley L, Klein AP, Maitra A, et al. Multifocal neoplastic precursor lesions associated with lobular atrophy of the pancreas in patients having a strong family history of pancreatic cancer. Am J Surg Patho. 2006 Sep;30(9):1067-76

9. Lowenfels AB, Maisonneuve P. Epidemiology and prevention of pancreatic cancer. Jpn J Clin Oncol. 2004 May;34(5):238-44

10. Kouvaraki MA, Shapiro SE, Cote GJ, Lee JE, Yao JC, Waguespack SG, et al. Management of pancreatic endocrine tumors in multiple endocrine neoplasia type 1. World J Surg. 2006 May;30(5):643-53

11. Blansfield JA, Choyke L, Morita SY, Choyke PL, Pingpank JF, Alexander HR, et al. Clinical, genetic and radiographic analysis of 108 patients with von Hippel-Lindau disease (VHL) manifested by pancreatic neuroendocrine neoplasms (PNETs). Surgery. 2007 Dec;142(6):814-8; discussion 818.e12

12. Artinyan A, Soriano PA, Prendergast C, Low T, Ellenhorn JDI, Kim J. The anatomic location of pancreatic cancer is a prognostic factor for survival. HPB (Oxford). 2008 Jan;10(5):371-6

13. Locker GY, Hamilton S, Harris J, Jessup JM, Kemeny N, Macdonald JS, et al. ASCO 2006 update of recommendations for the use of tumor markers in gastrointestinal cancer. J Clin Oncol. 2006 Nov 20;24(33):5313-27

14. Ballehaninna UK, Chamberlain RS. Serum CA 19-9 as a Biomarker for Pancreatic Cancer-A Comprehensive Review. Indian J Surg Oncol. 2011 
Jun;2(2):88-100

15. Rashleigh-Belcher HJ, Russell RC, Lees WR. Cutaneous seeding of pancreatic carcinoma by fineneedle aspiration biopsy. $\mathrm{Br} \quad \mathrm{J}$ Radiol. 1986 Feb;59(698):182-3

16. Margeret A. Tempero, Mokenge P. Malafa, Horacio Asbun, Stephen W. Behrman, Al B. Benson CC. Pancreatic Adenocarcinoma. 2. 2015

17. Al-Haddad M, Martin JK, Nguyen J, Pungpapong S, Raimondo M, Woodward T, et al. Vascular resection and reconstruction for pancreatic malignancy: a single center survival study. J Gastrointest Surg. 2007 Sep;11(9):1168-74

18. Pisters PW, Lee JE, Vauthey JN, Charnsangavej C, Evans DB. Laparoscopy in the staging of pancreatic cancer. Br J Surg. 2001 Mar;88(3):325-37

19. Malik NK, May KS, Chandrasekhar R, Wee W, Flaherty L, Iyer $R$, et al. Treatment of locally advanced unresectable pancreatic cancer: a 10-year experience. J Gastrointest Oncol. 2012 Dec;3(4):32634

20. Kalser MH, Ellenberg SS. Pancreatic cancer. Adjuvant combined radiation and chemotherapy following curative resection. Arch Surg. 1985 Aug;120(8):899-903

21. Neoptolemos JP, Stocken DD, Friess H, Bassi C, Dunn JA, Hickey H, et al. A randomized trial of chemoradiotherapy and chemotherapy after resection of pancreatic cancer. N Engl J Med. 2004 Mar 18;350(12):1200-10

22. Yang R, Cheung MC, Byrne MM, Jin X, Montero AJ, Jones C, et al. Survival effects of adjuvant chemoradiotherapy after resection for pancreatic carcinoma. Arch Surg. 2010 Jan;145(1):49-56

23. Oettle H, Post S, Neuhaus P, Gellert K, Langrehr J, Ridwelski K, et al. Adjuvant chemotherapy with gemcitabine vs observation in patients undergoing curative-intent resection of pancreatic cancer: a randomized controlled trial. JAMA. 2007 Jan 17;297(3):267-77

24. Bernhard J, Dietrich D, Scheithauer W, Gerber D, Bodoky G, Ruhstaller T, et al. Clinical benefit and quality of life in patients with advanced pancreatic cancer receiving gemcitabine plus capecitabine versus gemcitabine alone: a randomized multicenter phase III clinical trial--SAKK 44/00CECOG/PAN.1.3.001. J Clin Oncol. 2008 Aug 1;26(22):3695-701

25. Cunningham D, Chau I, Stocken DD, Valle JW, Smith D, Steward W, et al. Phase III randomized comparison of gemcitabine versus gemcitabine plus capecitabine in patients with advanced pancreatic cancer. J Clin Oncol. 2009 Nov 20;27(33):5513-8

26. Hariharan D, Saied A, Kocher HM. Analysis of mortality rates for pancreatic cancer across the world. HPB (Oxford). 2008 Jan;10(1):58-62
27. Banerjee J, Al-Wadei HAN, Schuller HM. Chronic nicotine inhibits the therapeutic effects of gemcitabine on pancreatic cancer in vitro and in mouse xenografts. Eur J Cancer. 2013 Mar;49(5):1152-8

28. Chang X, Ravi R, Pham V, Bedi A, Chatterjee A, Sidransky D. Adenylate kinase 3 sensitizes cells to cigarette smoke condensate vapor induced cisplatin resistance. PLoS One. 2011 Jan;6(6):e20806

29. Jamal MH, Doi SA, Simoneau E, Abou Khalil J, Hassanain M, Chaudhury $P$, et al. Unresectable pancreatic adenocarcinoma: do we know who survives? HPB (Oxford). 2010 Oct;12(8):561-6

30. Neuhaus P, Riess H, Post S, Gellert K, Ridwelski K, Schramm H, et al. CONKO-001: Final results of the randomized, prospective, multicenter phase III trial of adjuvant chemotherapy with gemcitabine versus observation in patients with resected pancreatic cancer (PC). ASCO Meet Abstr. 2008 May 20 ;26(15_suppl):LBA4504

31. Shinchi H, Takao S, Noma H, Matsuo Y, Mataki Y, Mori $\mathrm{S}$, et al. Length and quality of survival after external-beam radiotherapy with concurrent continuous 5-fluorouracil infusion for locally unresectable pancreatic cancer. Int $\mathrm{J}$ Radiat Oncol Biol Phys. 2002 May 1;53(1):146-50

32. Chauffert B, Mornex F, Bonnetain F, Rougier P, Mariette C, Bouché O, et al. Phase III trial comparing intensive induction chemoradiotherapy (60 Gy, infusional 5-FU and intermittent cisplatin) followed by maintenance gemcitabine with gemcitabine alone for locally advanced unresectable pancreatic cancer. Definitive results of the 2. Ann Oncol. 2008 Oct;19(9):1592-9

33. Ying J-E, Zhu L-M, Liu B-X. Developments in metastatic pancreatic cancer: is gemcitabine still the standard? World J Gastroenterol. 2012 Mar 28;18(8):736-45

34. Burris HA, Moore MJ, Andersen J, Green MR, Rothenberg ML, Modiano MR, et al. Improvements in survival and clinical benefit with gemcitabine as first-line therapy for patients with advanced pancreas cancer: a randomized trial. J Clin Oncol 1997 Jun;15(6):2403-13

35. Heinemann V, Quietzsch D, Gieseler F, Gonnermann M, Schönekäs H, Rost A, et al. Randomized phase III trial of gemcitabine plus cisplatin compared with gemcitabine alone in advanced pancreatic cancer. $\mathrm{J}$ Clin Oncol. 2006 Aug 20;24(24):3946-52

36. Colucci G, Labianca R, Di Costanzo F, Gebbia V, Cartenì G, Massidda B, et al. Randomized phase III trial of gemcitabine plus cisplatin compared with single-agent gemcitabine as first-line treatment of patients with advanced pancreatic cancer: the GIP-1 study. J Clin Oncol. 2010 Apr 1;28(10):1645-51 